\title{
PIOMETRAS EM CADELAS: RELAÇÃO ENTRE O PROGNÓSTICO CLÍNICO E O DIAGNÓSTICO LABORATORIAL
}

\section{PYOMETRA IN BITCHES: RELATIONSHIP BETWEEN CLINICAL PROGNOSIS AND LABORATORY DIAGNOSIS}

\author{
Luiz Guilherme Corsi Trautwein ${ }^{1 *}$ \\ Marcos Cezar Sant'Anna ${ }^{1}$ \\ Rebeca Cordeiro Justino ${ }^{1}$ \\ Lucienne Garcia Pretto Giordano ${ }^{1}$ \\ Karina Keller Marques da Costa Flaiban ${ }^{1}$ \\ Maria Isabel Mello Martins ${ }^{1}$ \\ ${ }^{1}$ Universidade Estadual de Londrina, Londrina, PR, Brasil. \\ *Autor para correspondência - contato@luizcorsi.vet.br
}

\section{Resumo}

Piometra é uma afecção resultante da interação bacteriana com a hiperplasia cística do endométrio. O objetivo deste estudo foi identificar bactérias em condições de aerobiose e anaerobiose da secreção intrauterina de cadelas com piometra, presença da síndrome da resposta inflamatória sistêmica, status da cérvix, peritonite, dosagens bioquímicas séricas e comparar com o prognóstico de cadelas tratadas cirurgicamente. Utilizaram-se 15 cadelas com piometra, submetidas à ovariohisterectomia. Hemogramas e dosagens séricas de ureia, creatinina, FA e ALT foram realizados no pré-operatório imediato. Coletou-se urina por cistocentese. Após a remoção do útero e ovários, a secreção intrauterina foi aspirada; as amostras foram então cultivadas em aerobiose e anaerobiose, as amostras de urina em aerobiose. Os animais foram divididos em dois grupos, G1 (alta hospitalar em até 48 horas) e G2 (alta hospitalar após 48 horas ou óbito). Onze amostras de conteúdo intrauterino (73,3\%) apresentaram crescimento bacteriano em aerobiose e anaerobiose e em uma amostra isolou-se Arizona hinshawii. Quatro amostras de urina (26,6\%) tiveram crescimento bacteriano. Houve diferença significativa das variáveis status da cérvix, ureia, creatinina e fosfatase alcalina entre G1 e G2. Embora a diversidade etiológica encontrada nas culturas de conteúdo intrauterino tenha sido alta, a avaliação da azotemia, status da cérvix e dosagem de FA sérica mostraram-se bons marcadores prognósticos em cadelas com piometra.

Palavras-chave: Anaerobiose; Creatinina; Hiperplasia Endometrial Cística; Microbiologia; SIRS.

\footnotetext{
Abstract

Pyometra is a disease resulting from bacterial interaction with cystic endometrial hyperplasia. The aim of this study was to identify bacteria under aerobic and anaerobic conditions of intrauterine
} 
secretion of bitches with pyometra, Systemic Inflammatory Response Syndrome, status of the cervix, peritonitis, serum biochemical measurements and to compare the prognosis of surgically treated bitches. We used 15 bitches with pyometra, undergoing ovariohysterectomy. Blood count and dosage of serum biochemicals were performed preoperatively. Urine was collected by cystocentesis during surgery. After the uterus was removed, intrauterine secretion was aspirated; the samples were grown aerobically and anaerobically, and urine aerobically. The animals were divided into two groups, G1 (hospital discharge until 48 hours) and G2 (discharged after 48 hours or death). Eleven samples of intrauterine content $(73.3 \%)$ had bacterial growth in aerobic and anaerobic conditions, and Arizona hinshawii was isolated in a sample. Four urine samples $(26.6 \%)$ had bacterial growth. There were significant differences in status of the cervix, urea, creatinine, alkaline phosphatase between G1 and G2. Although the etiology diversity found in intrauterine cultures was high, the evaluation of azotemia, status of the cervix, and serum alkaline phosphatase dosage proved to be good prognostics markers in female dogs with pyometra.

Keywords: anaerobic; creatinine; cystic endometrial hyperplasia; microbiology; SIRS.

Recebido em: 25 novembro de 2016

Aceito em: 27 junho de 2017

\section{Introdução}

O complexo hiperplasia endometrial cística (HEC) - Piometra é uma enfermidade caracterizada pelo acúmulo intrauterino de pus, que acomete 9 a 15,2\% de cadelas de meia idade a idosas. O tratamento pode ser cirúrgico, sendo realizada a ovariohisterectomia, ou medicamentoso, com fármacos antagonistas do receptor de progesterona ${ }^{(1,2)}$, ambos os tratamentos associados à antibioticoterapia. Essa afecção é responsável por grande parte dos atendimentos veterinários de caráter emergencial e, dependendo do microrganismo envolvido, pode levar o paciente ao óbito devido à endotoxemia ${ }^{(3,4)}$.

$\mathrm{Na}$ literatura, a taxa de isolamento bacteriano de conteúdo intrauterino de cadelas com piometra variou de 88,1 a $100 \%{ }^{(5-8)}$. Entretanto, em pesquisas recentes, 20 a $26 \%$ das culturas foram negativas, reforçando a necessidade de se estudar mais detalhadamente a etiologia bacteriana do conteúdo intrauterino de cadelas com piometra $^{(9,10)}$.

Embora a piometra seja uma afecção única, pode ser desencadeada por diferentes gêneros bacterianos e seu estudo se faz necessário para a determinação precisa da evolução da doença ${ }^{(11)}$, aliado à avaliação da síndrome da resposta inflamatória sistêmica (SIRS), a exame clínico e exames complementares, é de grande valia para a determinação do prognóstico ${ }^{(12)}$.

Sendo assim, o objetivo deste estudo foi comparar o isolamento e identificação de bactérias da secreção intrauterina, cultivadas em condições de aerobiose e anaerobiose, e da urina em aerobiose com a presença da SIRS, status da cérvix, peritonite e dosagens séricas de ureia, creatinina, fosfatase alcalina (FA) e alanina aminotransferase (ALT) com o prognóstico de cadelas tratadas cirurgicamente. 


\section{Material e Métodos}

O experimento foi aprovado pelo Comitê de Ética em Experimentação Animal (nº 18/10). Todos os procedimentos aos quais os animais foram submetidos tiveram prévia autorização dos tutores.

Foram utilizadas 15 cadelas com diagnóstico clínico de piometra. Todos os animais foram submetidos a tratamento cirúrgico (ovariohisterectomia) associado à fluidoterapia, antibioticoterapia e acompanhamento clínico no pós-operatório.

O diagnóstico de piometra nas cadelas foi realizado pela associação de dados da anamnese, exame físico, exames hematológicos e observação de aumento uterino nos exames de imagem como raio-x e/ou ultrassonografia.

No pré-operatório, durante o exame clínico, foi realizada coleta de sangue por venopunção da veia jugular externa. O sangue foi aliquotado em dois tubos plásticos, um contendo anticoagulante ácido etilenodiamino tetra-acético (EDTA), para realização de hemograma e contagem de plaquetas, e um tubo seco para extração e armazenamento do soro a $-20^{\circ} \mathrm{C}$.

O hemograma foi realizado por meio da espectofotometria (BS 120, Mindray®, China). As alterações morfológicas das hemácias, contagem de plaquetas e a contagem diferencial dos leucócitos foram avaliadas através de esfregaço sanguíneo com coloração tipo Romanowisky (Panótipo rápido, Laborclin ${ }$, Pinhais, Brasil). O soro foi descongelado à temperatura ambiente e determinou-se a atividade sérica das enzimas Fosfatase Alcalina (FA) e Alanina Aminotransferase (ALT) através do método cinético, as dosagens de ureia e creatinina foram realizadas pelo método colorimétrico em espectofotômetro (Dimension RXL®, Siemens, Erlangen, Alemanha).

Após a estabilização do paciente, foi realizada a ovariohisterectomia. Para indução foi utilizado propofol (6 mg/kg), isofluorano para manutenção anestésica e tramadol (3 mg/kg) para analgesia. Durante a cirurgia foi realizada a cistocentese. Após a remoção do útero, foi colhido conteúdo intrauterino, por punção asséptica. Imediatamente após, as amostras de urina e de conteúdo intrauterino foram encaminhados para isolamento bacteriano.

Para a cultura da urina, $1 \mathrm{~mL}$ foi semeado em $9 \mathrm{~mL}$ de Caldo de Infusão de Cérebro e Coração (Brain and Heart Infusion, Biobrás ${ }^{\circledR}$, Montes Claros, Brasil) e incubado em condições de aerobiose a $37^{\circ} \mathrm{C}$ por até 48 horas. Os caldos com crescimento foram repicados em ágar sangue ovino a 5\% (Himedia®, Mumbai, Índia) e incubados a $37^{\circ} \mathrm{C}$ em aerobiose por até 48 horas.

O conteúdo intrauterino foi semeado diretamente em duas placas de ágar sangue. Uma placa foi incubada em aerobiose por até 48 horas e a outra foi incubada em jarra de anaerobiose (GasPak ${ }^{\mathrm{TM}} \mathrm{EZ}$ Anaerobe Container System, Sparks, USA), a $37{ }^{\circ} \mathrm{C}$ por até 48 horas. O controle da anaerobiose foi realizado com tira reagente para anaerobiose (BBL ${ }^{\text {тм }}$ Dry Anaerobic Indicator Strips, Sparks, USA).

Foram analisadas as características culturais, morfológicas, tintoriais e bioquímicas dos microrganismos isolados pela Coloração de Gram, prova da catalase, coagulase, oxidase, esculina e $\mathrm{NaCl}$ 6,5\%. Bactérias Gram negativas foram semeadas em meio seletivo MacConkey e identificadas pelo sistema Bactray (Laborclin®, Pinhais, Brasil). 
A presença de peritonite foi avaliada pelas alterações nos exames de imagem e visualmente no transcirúrgico. O status de cérvix foi classificado em piometra aberta, quando havia a presença de secreção vaginal piossanguinolenta e ou purulenta, e piometra fechada quando não havia secreção vaginal.

Para a análise dos dados, os pacientes foram distribuídos em dois grupos: Grupo 1 (G1) para cadelas que necessitaram de menos de 48 horas de internação após o tratamento cirúrgico; e o Grupo 2 (G2) para cadelas que necessitaram de mais que 48 horas de internação e/ou vieram à óbito.

A classificação como SIRS positivo ou negativo foi de acordo com os critérios estabelecidos por Hauptman et al. ${ }^{(13)}$, com sensibilidade de $97 \%$ e especificidade de $64 \%$. Foram consideradas positivas para SIRS aquelas cadelas que apresentaram dois ou mais dos seguintes critérios: 1) frequência cardíaca > $120 \mathrm{bpm}$; 2) frequência respiratória > $20 \mathrm{mpm}$; 3) temperatura retal acima de $39,2^{\circ} \mathrm{C}$ ou abaixo de $38,1^{\circ} \mathrm{C}$; 4) número de leucócitos totais acima de 16.000 ou abaixo de 6.000 ou ainda mais que $3 \%$ de bastonetes.

Para a associação das variáveis SIRS, peritonite e status de cérvix com relação à morbidade e/ou mortalidade dos casos estudados, foi utilizado o teste exato de Fisher. Para a comparação dos resultados hematológicos e bioquímicos entre os grupos foi realizado o teste Mann-Whitney. Os testes foram realizados no programa estatístico Epi Info 7 (CDC, Atlanta, USA), nível de significância de $5 \%$.

\section{Resultados}

Dentre as 15 cadelas estudadas, sete $(46,7 \%)$ eram sem raça definida, enquanto as raças Poodle e Shar Pei foram representadas por dois $(13,3 \%)$ animais cada, seguidas de um exemplar de Cocker Spaniel Americano, Dog Alemão, American Pit Bull Terrier e Shih Tzu (6,7\% cada). A média de idade das pacientes foi $8,4 \pm 3,5$ anos e a média de peso corporal foi $15,3 \pm 11,3 \mathrm{~kg}$.

Das 15 amostras de conteúdo intrauterino, $11(73,3 \%)$ apresentaram crescimento bacteriano em aerobiose e $11(73,3 \%)$ em anaerobiose (Tabela 1). Em quatro (26,7\%) amostras não houve crescimento bacteriano.

Os resultados das culturas de secreção uterina foram semelhantes em condição de aerobiose e anaerobiose, afinal são anaeróbicas facultativas. Exceto em duas amostras, em que foi identificado $A$. hinshawii na condição anaeróbica, e Proteus spp em aerobiose. Em uma segunda amostra, em aerobiose foi isolado Staphylococcus spp e, em anaerobiose, Staphylococcus spp e Streptococcus spp.

Das 15 amostras de urina, somente em quatro $(26,7 \%)$ houve crescimento bacteriano, Escherichia coli, Pseudomonas spp, Streptococcus spp, e Bacilos Gram negativos, lactose e oxidase negativa, não identificado pelo sistema Bactray. 
Tabela 1. Bactérias isoladas e identificadas a partir de 11 amostras de secreção uterina de quinze cadelas com piometra tratadas cirurgicamente

\begin{tabular}{lllll}
\hline \multicolumn{1}{c}{ Isolamento } & \multicolumn{2}{c}{ Aerobiose } & \multicolumn{2}{c}{ Anaerobiose } \\
& Amostras & Porcentagem & Amostras & Porcentagem \\
\hline $\begin{array}{l}\text { Arizona hinshawii } \\
\text { Bacilos gram negativos, }\end{array}$ & 1 & - & 1 & $9,09 \%$ \\
oxidase negativa* & $9,09 \%$ & 1 & $9,09 \%$ \\
Escherichia coli & 2 & $18,18 \%$ & 2 & $18,18 \%$ \\
Klebsiella spp & 1 & $9,09 \%$ & 1 & $9,09 \%$ \\
Proteus spp & 1 & $9,09 \%$ & - & - \\
Pseudomonas spp & 1 & $9,09 \%$ & 1 & $9,09 \%$ \\
Staphylococcus spp & 1 & $9,09 \%$ & - & - \\
Streptococcus spp & 2 & $18,18 \%$ & 2 & $18,18 \%$ \\
$\begin{array}{l}\text { Streptococcus } \text { spp } \mathrm{e} \\
\text { Pasteurella } \text { spp }\end{array}$ & 1 & $9,09 \%$ & 1 & $9,09 \%$ \\
$\begin{array}{l}\text { Streptococcus } \text { spp } \mathrm{e} \\
\text { Staphylococcus } \text { spp }\end{array}$ & 1 & $9,09 \%$ & 2 & $18,18 \%$ \\
\hline Total de amostras & $11 / 15$ & $100 \%$ & $11 / 15$ & $100 \%$ \\
\hline
\end{tabular}

*Isolado não identificado pelo teste utilizado.

Dentre as cadelas estudadas, cinco (33,3\%) foram alocadas no G1 e dez $(66,7 \%)$ alocadas no G2, das quais oito tiveram período de internamento superior a 48 horas e duas cadelas vieram a óbito.

As variáveis SIRS, peritonite e status de cérvix foram comparadas com G1 e G2 para sua influência ou não na morbidade e/ou mortalidade de cadelas com piometra. Apenas a variável status de cérvix apresentou associação significativa (Tabela 2).

As variáveis relacionadas ao hemograma e leucograma também foram comparadas entre G1 e G2 para verificação de associação entre estes exames hematológicos e a necessidade de internação prolongada e/ou óbito em cadelas com piometra tratadas cirurgicamente. Não houve diferença significativa em nenhuma das variáveis (quantidade de hemácias, volume globular, hemoglobina, leucócitos, segmentados, bastonetes e linfócitos).

A comparação entre os grupos dos valores referentes aos exames bioquímicos está descrita na Tabela 3. Houve diferença significativa quando avaliadas as variáveis ureia, creatinina e FA. 
Tabela 2. Frequência e associação das variáveis SIRS, peritonite e status de cérvix de cadelas com piometra tratadas cirurgicamente, com a necessidade de internação menor que 48 horas (G1) e acima de 48 h e/ou óbito (G2) utilizando o teste exato de Fisher com nível de significância de $5 \%$

\begin{tabular}{lccc}
\hline \multicolumn{1}{c}{ Variáveis } & G1 & G2 & Valor de \\
& $\mathrm{n} /$ total $(\%)$ & $\mathrm{n} /$ total $(\%)$ & \\
\hline SIRS & & & 0,57 \\
Sim & $4 / 13(30,8 \%)$ & $9 / 13(69,3 \%)$ & \\
Não & $1 / 2(50 \%)$ & $1 / 2(50 \%)$ & 0,40 \\
Peritonite & $2 / 4(50 \%)$ & $2 / 4(50 \%)$ & \\
Sim & $3 / 11(27,8 \%)$ & $8 / 11(72,7)$ & $0,04 *$ \\
Não & & & \\
Status da Cérvix & $5 / 9(55,56 \%)$ & $4 / 9(44,4 \%)$ & \\
Aberta & $0 / 6(0 \%)$ & $6 / 6(100 \%)$ & \\
Fechada & & & \\
\hline
\end{tabular}

*Associação significativa

Tabela 3. Mediana (mínimo-máximo) dos valores de ureia, creatinina, FA e ALT de cadelas com piometra tratadas cirurgicamente e a comparação da necessidade de internação menor que 48 horas (G1) e acima de 48 h e/ou óbito (G2) por meio do teste de Mann-Whitney com nivel de significância de 5\%

\begin{tabular}{lccc}
\hline \multicolumn{1}{c}{ Variáveis } & G1 & G2 & Valor de p \\
\hline Ureia (mg/dl) & 27 & 83 & $0,01^{*}$ \\
Creatinina (mg/dl) & $(21-45)$ & $(23-264)$ & \\
& $(0,3-1,4)$ & 2,2 & $0,01^{*}$ \\
FA (UI/L) & 74 & $(1-8,7)$ & $0,03^{*}$ \\
& $(16-198)$ & 249 & \\
ALT (UI/L) & 23 & $(55-2009)$ & 0,9 \\
\hline
\end{tabular}

*Associação significativa 


\section{Discussão}

O número de amostras negativas à semeadura do conteúdo uterino foi $26,7 \%$, tanto em condição de aerobiose quanto em anaerobiose, resultados semelhantes aos de Trautwein et al. ${ }^{(10)}$ (20\% de 20 cadelas com piometra) e aos de Sant'Anna et al. ${ }^{(9)}$ (26,3\% de 80 fêmeas).

Arizona hinshawii, que pertence à família Enterobacteriaceae, foi anteriormente isolada em trato gastrointestinal de répteis e aves e em casos de pielonefrite e meningite em neonatos humanos ${ }^{(14,15)}$. Não há na literatura disponível relatos de isolamento de A. hinshawii em conteúdo intrauterino de cadelas com piometra, demonstrando a necessidade de mais pesquisas com diferentes técnicas de identificação bacteriana.

A frequência de isolamento de Escherichia coli foi de $18 \%$, embora na literatura este agente seja relatado como o principal microrganismo envolvido na patogenia da piometra canina, com prevalência variando de 40,5 a $96 \%{ }^{(5,7,16-18)}$. Os resultados desse estudo (18\%) foram mais baixos que o de outros autores nacionais, que relataram frequência de 36 a $55 \%{ }^{(8,9,11,19)}$.

Essas diferenças encontradas podem ser explicadas pela variedade de antibióticos e seu uso indiscriminado em animais de companhia ${ }^{(9,20)}$. Em estudos internacionais, em cadelas com piometra, a resistência bacteriana a antibióticos como a ampicilina foi de $10 \%$ e à enrofloxacina $4 \%{ }^{(21)}$, enquanto estudos nacionais mostraram resistência bacteriana de $60 \%$ à ampicilina e $12,5 \%$ à enrofloxacina ${ }^{(5)}$. Isso demonstra que o uso incorreto de antimicrobianos pode favorecer a seleção de microrganismos resistentes ${ }^{(22)}$, colocando em risco não somente os animais de estimação como também a saúde de pessoas por meio do convívio domiciliar ${ }^{(23)}$.

A realização de cultura e antibiograma de conteúdo intrauterino é importante, principalmente devido à elevada taxa de multirresistência apresentada em estudos recentes ${ }^{(8,9,19)}$. A escolha correta do antibiótico, além de influenciar diretamente no tratamento, é fundamental do ponto de vista da saúde pública, devido ao aumento da frequência de seres humanos com infecções graves em Unidades de Terapia Intensiva, com alto custo de tratamento e índice de mortalidade elevado ${ }^{(23)}$, além do surgimento de inúmeros casos de "superbactérias" multirresistentes ${ }^{(24,25)}$.

Algumas cadelas apresentaram cultura urinária positiva; entretanto, nenhuma delas apresentou sinais clínicos referentes à infecção urinária. Hagman e $\mathrm{Kuhn}^{(26)}$ haviam sugerido que as espécies bacterianas são as mesmas em casos de infecção simultânea de trato urinário e piometra.

Embora alguns trabalhos não tenham relatado diferença significativa entre o status de cérvix relacionado ao prognóstico ${ }^{(9,10)}$, evidenciou-se a alta frequência de piometra de cérvix fechada em cadelas que necessitaram de mais de 48 horas de internação e/ou vieram a óbito. Esta relação positiva corrobora o conceito de que as piometras fechadas são mais graves, relacionadas à maior taxa de leucocitose, ureia e FA séricas ${ }^{(27)}$.

A diferença nos níveis séricos de ureia e creatinina mostraram-se de acordo com outros estudos ${ }^{(6,9,10)}$, confirmando que os resultados dessas dosagens podem ser de grande valia na avaliação prognóstica dessa doença. Este aumento pode estar relacionado a causas extra-renais, em consequência do maior 
catabolismo proteico associado a processos infecciosos graves ${ }^{(28)}$, ou podem estar relacionado à desidratação e à reduzida perfusão renal e/ou toxemia ${ }^{(29,30)}$.

É importante salientar que a fluidoterapia, preferencialmente com uma solução hidroeletrolítica balanceada, como o Ringer com lactato, é fundamental para a recuperação destes animais e reversão da azotemia, assegurando adequada perfusão tecidual ${ }^{(3,18)}$.

Aumento significativo na FA no G2 foi detectado, quando comparado ao G1, e pode ser resultado de colestase intra-hepática, ao invés de dano especificamente hepático, caracterizado pela baixa atividade de $\mathrm{ALT}^{(18)}$, ou refere-se ao aumento da atividade desta enzima por ação de corticoides endógenos, devido ao estresse e à dor causada pelo quadro infeccioso ${ }^{(31)}$.

Para a rotina do médico veterinário, a avaliação diagnóstica e, principalmente, prognóstica da piometra canina são de grande importância para a evolução clínica da doença e para a comunicação entre o profissional e o proprietário. A avaliação de exames bioquímicos e biomarcadores tem-se mostrado uma ferramenta fundamental para o diagnóstico precoce das complicações, podendo, muitas vezes, predizer a morbidade e a mortalidade da doença ${ }^{(1,9,11,32)}$.

\section{Conclusão}

Baixas concentrações séricas de creatinina, ureia e FA e status da cérvix aberta foram associados a um tempo de internação menor que 48 horas em cadelas com piometra, mostrando-se bons marcadores prognósticos para esta doença. A realização da cultura e antibiograma do conteúdo intrauterino é fundamental na escolha do antibiótico para que o tratamento seja eficaz.

\section{Referências}

1. Jitpean S, Strom-Holst B, Emanuelson U, Hoglund OV, Pettersson A, Alneryd-Bull C, et al. Outcome of pyometra in female dogs and predictors of peritonitis and prolonged postoperative hospitalization in surgically treated cases. BMC Vet Res. 2014;10:6.

2. Ros L, Holst BS, Hagman R. A retrospective study of bitches with pyometra, medically treated with aglepristone. Theriogenology. 2014;82(9):1281-6.

3. Barsanti JA. Genitourinary infections. In: Greene CE, editor. Infectious Diseases of the Dog and Cat. 1. 4th ed. Georgia: Elsevier; 2012. p. 1376.

4. Pretzer SD. Clinical presentation of canine pyometra and mucometra: a review. Theriogenology. 2008;70(3):359-63.

5. Coggan JA, Melville PA, Oliveira CMd, Faustino M, Moreno AM, Benites NR. Microbiological and histopathological aspects of canine pyometra. Brazilian Journal of Microbiology. 2008;39:477-83. 
6. Küplülü S, Vural MR, Demirel A, Polat M, Akçay A. The comparative evaluation of serum biochemical, haematological, bacteriological and clinical findings of dead and recovered bitches with pyometra in the postoperative process. Acta veterinaria. 2009;59(2-3):193-204.

7. Fransson B, Lagerstedt AS, Hellmen E, Jonsson P. Bacteriological findings, blood chemistry profile and plasma endotoxin levels in bitches with pyometra or other uterine diseases. Zentralblatt fur Veterinarmedizin Reihe A1997;44(7):417-26.

8. Oliveira FS, Paz LN, Mota TM, Oriá AP, da Silva MCA, Pinna MH. Perfil de resistência de isolados de Escherichia coli a partir de piometra canina. Cienc anim bras. 2016;17(3):615-21.

9. Sant'Anna MC, Giordano LGP, Flaiban KKMC, Muller EE, Martins MIM. Prognostic markers of canine pyometra. Arquivo Brasileiro de Medicina Veterinária e Zootecnia. 2014;66:1711-7.

10. Trautwein LGC, Sant'Anna MC, Giordano LGP, Muller EE, Flaiban KKMC, Alves RIA, et al. Avaliação microbiológica e biomarcadores em cadelas com piometra. Journal Brasileiro de Ciênca Animal. 2012;5(10):159-61.

11. Trautwein LGC, Justino R, Sant'Anna MC, Flaiban KKMC, Pretto-Giordano LG, Martins MIM. A importância dos micro-organismos isolados da secreção uterina na patogenicidade da piometra canina. Anais do XX Congresso Brasileiro de Reprodução Animal. 2013;20(01):189.

12. Fransson BA, Lagerstedt A-S, Bergstrom A, Hagman R, Park JS, Chew BP, et al. C-reactive protein, tumor necrosis factor $\alpha$, and interleukin-6 in dogs with pyometra and SIRS. Journal of Veterinary Emergency and Critical Care. 2007;17(4):373-81.

13. Hauptman JG, Walshaw R, Olivier NB. Evaluation of the sensitivity and specificity of diagnostic criteria for sepsis in dogs. Veterinary surgery : VS. 1997;26(5):393-7.

14. Jarvis WR, Luce WD, Baltimore R. Arizona hinshawii Meningitis in a Neonate. Clinical Pediatrics. 1981;20(7):483-4.

15. Rushton AR. Pyelonephritis Due to Multiply Drug-resistant Arizona hinshawii. Clinical Pediatrics. 1983;22(6):435.

16. Grindlay M, Renton JP, Ramsay DH. O-groups of Escherichia coli associated with canine pyometra. Research in veterinary science. 1973;14(1):75-7.

17. Dhaliwal GK, Wray C, Noakes DE. Uterine bacterial flora and uterine lesions in bitches with cystic endometrial hyperplasia (pyometra). The Veterinary record 1998;143(24):659-61.

18. Fransson BA, Ragle CA. Canine pyometra: an update on pathogenesis and treatment. Compendium on Continuing Education for the Practising Veterinarian -North American Edition. 2003;25(8):602-13.

19. Weiss RR, Calomeno MA, Sousa RS, Muradas PR. Avaliação histopatológica, hormonal e bacteriológica da piometra na cadela. Archives of Veterinary Science. 2004;9(2):81-7.

20. Pedersen K, Pedersen K, Jensen H, Finster K, Jensen VF, Heuer OE. Occurrence of antimicrobial resistance in bacteria from diagnostic samples from dogs. The Journal of antimicrobial chemotherapy 2007;60(4):775-81.

21. Hagman R, Greko C. Antimicrobial resistance in Escherichia coli isolated from bitches with pyometra and from urine samples from other dogs. The Veterinary record 2005;157(7):193-6.

22. Sullivan A, Edlund C, Nord CE. Effect of antimicrobial agents on the ecological balance of human microflora. The Lancet Infectious diseases 2001;1(2):101-14. 
23. Arias MVB, Carrilho CMD. Resistência antimicrobiana nos animais e no ser humano. Há motivo para preocupação? Semina: Ciências Agrárias. 2012;33(2):775-90.

24. Huo TI. The first case of multidrug-resistant NDM-1-harboring Enterobacteriaceae in Taiwan: here comes the superbacteria! J Chin Med Assoc. 2010;73(11):557-8.

25. Guh AY, Limbago BM, Kallen AJ. Epidemiology and prevention of carbapenem-resistant Enterobacteriaceae in the United States. Expert Rev Anti Infect Ther. 2014;12(5):565-80.

26. Hagman R, Kuhn I. Escherichia coli strains isolated from the uterus and urinary bladder of bitches suffering from pyometra: comparison by restriction enzyme digestion and pulsed-field gel electrophoresis. Veterinary microbiology. 2002;84(1-2):143-53.

27. Yu IJ. Hematological and Serum Chemical Characteristics of Open-Cervix and Closed-Cervix Pyometra in Bitches. Journal of Animal and Veterinary Advances. 2012;11(19):3658-61.

28. Cockcroft PD. Focal cystic endometrial hyperplasia in a bitch. The Journal of small animal practice 1995;36(2):77-8.

29. Verstegen J, Dhaliwal G, Verstegen-Onclin K. Mucometra, cystic endometrial hyperplasia, and pyometra in the bitch: advances in treatment and assessment of future reproductive success. Theriogenology. 2008;70(3):364-74.

30. Nath K, Tiwari SK, Sharda R, Kalim MO. Pyometra induced biochemical changes in bitches. The indian veterinary journal. 2009;86(8):853-5.

31. Lassend ED. Avaliação laboratorial do fígado. In: Thrall MA, editor. Hematologia e Bioquímica Clínica Veterinária. 01. 1 st ed. São Paulo: Roca; 2007. p. 592.

32. Jitpean S, Holst BS, Hoglund OV, Pettersson A, Olsson U, Strage E, et al. Serum insulin-like growth factor-I, iron, C-reactive protein, and serum amyloid A for prediction of outcome in dogs with pyometra. Theriogenology. 2014;82(1):43-8. 